\title{
Effect of variations in layer thickness and resilience modulus on flexible pavement
}

\section{performance}

\author{
Efeito das variações das espessuras e módulos de resiliência das camadas no desempenho de \\ pavimentos flexíveis
}

Efecto de las variaciones en los espesores de capa y el módulo de resiliencia sobre el comportamiento de los pavimentos flexibles

Received: 06/22/2021 | Reviewed: 06/28/2021 | Accept: 07/02/2021 | Published: 07/15/2021

\author{
Thaís Ferrari Réus \\ ORCID: https://orcid.org/0000-0001-9843-6715 \\ City Hall of Maringá, Brazil \\ E-mail: thaisferrarireus@gmail.com \\ Heliana Barbosa Fontenele \\ ORCID: https://orcid.org/0000-0003-2046-0568 \\ State University of Londrina, Brazil \\ E-mail: heliana@uel.br
}

\begin{abstract}
A pavement mechanistic-empirical analysis is based on a pre-designed structure checked for required performance criteria. In case the latter are not met, this structure is modified and reprocessed. In this context, analyzing the effect of variations in project parameters on pavement performance prediction subsidizes a better understanding of results provided by computer programs. The objective of this study is to assess the effect of layer thickness and resilience modulus variations on flexible pavement performance. To do so, performance was estimated for the 20th project year through Elastic Layered System Model 5 (ELSYM5) software and American Association of State Highway and Transportation Officials (AASHTO) Mechanistic-Empirical method (ME). Using multiple regression models for result adjustment and through statistical assessments on regression coefficients calculated, it can be concluded that pavement lifespan consumption, predicted by simulations on ELSYM5, is sensitive to variations in coating and subbase thickness and in subgrade resilience modulus. For AASHTO ME method, predicted values for distresses were significantly sensitive to variations in coating, base and subbase thickness, and in base and subgrade resilience modulus. Comparing both approaches, it is concluded that ELSYM5 can be a viable alternative to the application of a ME pavement design method.
\end{abstract}

Keywords: Design; Empirical-mechanistic; Structural responses; Distresses.

\section{Resumo}

A análise empírico-mecanística de um pavimento parte de uma estrutura pré-dimensionada que é verificada quanto aos critérios de desempenho requeridos. Caso estes não sejam atendidos, essa estrutura é modificada e reprocessada. Neste contexto a análise do efeito das variações nos parâmetros de projeto na previsão do desempenho do pavimento fornece subsídio para uma melhor compreensão dos resultados fornecidos pelos programas computacionais. O objetivo deste trabalho é avaliar o efeito das variações das espessuras e módulos de resiliência das camadas no desempenho dos pavimentos flexíveis. Para tanto, foram feitas estimativas de desempenho utilizando o programa Elastic Layered System Model 5 (ELSYM5) e o método Empírico Mecanístico (E-M) da American Association of State Highway and Transportation Officials (AASHTO). Utilizando modelos de regressão múltipla para o ajuste dos resultados e, pela avaliação estatística dos coeficientes de regressão obtidos, pode-se concluir que o consumo da vida útil do pavimento, previsto com simulações no ELSYM5, é sensível às variações das espessuras do revestimento e da sub-base e dos módulos de resiliência do subleito. Para o método E-M da AASHTO os valores previstos para os defeitos foram significativamente sensíveis às variações das espessuras do revestimento, da base e da sub-base e dos módulos de resiliência da base e do subleito. A partir da comparação das duas abordagens, concluiu-se que o ELSYM5 pode ser uma alternativa viável para a aplicação de um método E-M de dimensionamento de pavimentos.

Palavras-chave: Dimensionamento; Empírico-mecanístico; Respostas estruturais; Defeitos.

\section{Resumen}

El análisis empírico-mecanicista de un pavimento parte de una estructura predimensionada que se verifica para los criterios de desempeño requeridos. Si no se cumplen, se modifica y se vuelve a procesar. En este contexto, el análisis del efecto de las variaciones en los parámetros de diseño sobre la predicción del desempeño del pavimento proporciona 
soporte para una mejor comprensión de los resultados proporcionados por los programas informáticos. El objetivo de este trabajo es evaluar el efecto de las variaciones de espesor y módulo de resiliencia de capas sobre el comportamiento de pavimentos flexibles. Para ello, se realizaron estimaciones de rendimiento utilizando el programa Elastic Layered System Model 5 (ELSYM5) y el método empírico mecanicista (E-M) de American Association of State Highway and Transportation Officials (AASHTO). Utilizando modelos de regresión múltiple para ajustar los resultados y, a través de la evaluación estadística de los coeficientes de regresión obtenidos, se puede concluir que el consumo de la vida útil del pavimento, pronosticado con simulaciones en ELSYM5, es sensible a variaciones en el espesor del pavimento. revestimiento y los módulos de resiliencia de subbase y subrasante. Para el método AASHTO E-M, los valores predichos para los distressos fueron significativamente sensibles a las variaciones en el espesor del recubrimiento, base y subbase y en los módulos de resiliencia de la base y subrasante. De la comparación de los dos enfoques, se concluyó que ELSYM5 puede ser una alternativa viable para la aplicación de un método de diseño de pavimentos E-M.

Palabras clave: Dimensionamiento; Empírico-mecanicista; Respuestas estructurales; Defectos.

\section{Introduction}

Pavement design based on mechanistic-empirical methods are becoming increasingly promising for being currently described as the approach that is more in line with the reality of the field. Pavement analysis by this method relies on a predesigned structure for which structural responses are determined and damages accumulated throughout the project lifespan are calculated. Results obtained allow verifying compliance with project criteria from the initial structure. In case these criteria are not met, variations are applied to this structure, and the method is repeated until the condition established is reached.

In this context, analyzing the effect of project parameter variations subsidizes a better understanding of how results provided by computer programs behave through input variables. In addition, knowing how each parameter influences distress prediction can help designers decide on which parameter should be subjected to variation for the best resolution of the problem presented in the analysis. Studies carried out in order to observe such behaviors are known as sensitivity analysis.

The sensitivity of distress prediction by Mechanistic Empirical Pavement Design Guide (MEPDG) software according to pavement layer thickness variations was verified by Pelisson, Fernandes, Silva, and Fontenele (2015). The results that the authors found showed that increases in asphalt coating thickness from 7.5 to $15 \mathrm{~cm}$ reduce all distresses, with the higher impact being on fatigue cracking. Base thickness variation caused considerable reductions only for fatigue cracking; as for permanent deformations and the International Roughness Index (IRI), they showed little sensitivity. About subbase thickness variation, distresses were little or not at all sensitive.

As well as the research mentioned above asphalt coating thickness variation was also studied by Vidotto and Fontenele (2013), but in this study ELSYM5 computer program was used for structural response calculation. ELSYM5 is a computer program that applies the theory of elastic layer system that considers as inputs the number of layers (up to 5), their thicknesses, modulus of elasticity and Poisson coefficients, the location and magnitude of the loads per wheel and coordinates for determining pavement responses. From structural responses obtained in the study, the authors determined the mechanistic-empirical Equivalent Standard Axle Load (ESAL) for cracking and deformations. They concluded that both distresses are sensitive to the data analyzed.

Layer resilience modulus variation was studied by Alexandre et al. (2015), who also used ELSYM5 computer program to determine pavement structural responses. As per results, they concluded that, with base resilience modulus variation, the deformation responsible for appearance of fatigue cracking is more sensitive than that related to rutting, and there is deterioration as the parameter increases. As for the subbase layer, they observed low sensitivity to resilience modulus variation. Regarding the subgrade, sensitivity was considered as very low for cracking, but expressive for rutting. The sensitivity of distress prediction by MEPDG software as to variations in granular material properties (layer thickness, resilience modulus, plasticity index, liquidity threshold, etc.), elements of a pavement base and subgrade, was studied by Li, Schwartz, Kim and Ceylan (2012). Base and subgrade resilience modulus and base thickness are the properties with the greatest influence on performance prediction for all criteria, regardless of traffic volume. Poisson's ratio for base and subgrade presented sensitivity as well. Still according to the 
authors, fatigue cracking represents the performance parameter that is most sensitive to variations in granular material properties, while bottom-up cracking and rutting proved to be insensitive to variations in these properties.

The influence of material properties on performance predicted by MEPDG software was also the study object of Orobio and Zaniewski $(2011,2012)$. The research employed a pavement composed of three asphalt concrete layers, a fourth layer made up of a bitumen-treated permeable base, and the subgrade. Cracking prediction was sensitive to Poisson's ratio variations for the first four layers, for the void ratio of the first three, for the binder content of the first, third and fourth layers, and for the subgrade resilience modulus. When it comes to rutting, there was sensitivity as to variations in the following items: Poisson's ratios, void ratios and binder contents for the first two layers; the fourth layer void ratios, and the subgrade resilience modulus. About IRI prediction, there was sensitivity as to variations of the following items: Poisson's ratios, void ratios and binder contents for the first three layers; the fourth layer binder content; and the subgrade resilience modulus.

In addition to properties of materials, traffic also plays a major role in performance prediction, as discussed by Orobio and Zaniewski (2013). The study conducted addressed the sensitivity of MEPDG software results as to traffic input data variations. The authors found that IRI, rutting and bottom-up cracking are more sensitive to Annual Average Daily Traffic (AADT). Although these parameters are not controlled by designers, the research results show that they should be carefully assessed.

Another parameter that should be taken into account is tire inflation pressure because, as verified by Fontenele and Fernandes (2014), a tire pressure increase from $563 \mathrm{kPa}$ to $844 \mathrm{kPa}$ reduced the pavement predicted life between 50\% and 60\%, concerning rutting, and by $24 \%$, when it comes to fatigue cracking, according to values predicted on MEPDG software.

Several other studies concerning the sensitivity of the mechanistic-empirical method to design parameters developed over the last 10 years can also be cited, such as: Schwartz, Li, Ceylan, Kim and Gopalakrishnan (2013) performed with the results of the MEPDG software a global sensitivity analysis with parameters related to materials and traffic through random sampling techniques; Mai, Turochy and Timm $(2013,2014)$ used local sensitivity analysis of traffic input data in the MEPDG software to quantify the effects of different traffic characterizations on pavement performance; Li, Zhang, Zhao and Wang (2014) performed global sensitivity analyzes using simple factorial experiments varying the traffic and materials parameters in MEPDG; Cooper, Elseifi and Mohammad (2014) used variations from a full factorial experiment on coating and base layer thicknesses, base layer resilience moduli, subgrade types and traffic levels to verify the sensitivity of the responses provided by the MEPDG program; Hossain, Singh and Zaman (2016) studied the sensitivity of the ruttings predicted by AASHTOWare Pavement ME Design from the variation of traffic input parameters; Ranadive and Tapase (2016) used the finite element technique to analyze the sensitivity of pavement performance parameters from the variation of thickness and material properties of different layers of the structure; Yang, You, Hiller and Watkins (2017) used the AASHTOWare Pavement ME Design software to apply a local sensitivity analysis considering the variation of traffic volumes and climate parameters; Harsini, Haider, Brink, Buch and Chatti (2018) investigated, from a global sensitivity analysis, the parameters that are important for the pavement rehabilitation project using the AASHTOWare Pavement ME Design program; Koshigoe, Zanoni, Silva and Fontenele (2019) compared the sensitivity of the variation of the average daily volume and traffic growth rate on flexible pavements performance resulting from the use of the computer programs MEPDG and AASHTOWare Pavement ME Design; Li, Minnekanti, Yang and Wang (2019) applied sensitivity analyzes to assess pavement performance subject to various levels of traffic input data in the AASHTOWare Pavement ME Design software; Santos, Silva and Fontenele (2019) compared the sensitivity observed by the performance analyzes generated by the MEPDG and AASHTOWare Pavement ME Design computer programs regarding the use of the program's standard load spectra (values generated from US data) and those developed with traffic data from the Imigrantes highway in Brazil.

As can be seen, the studies reported used different techniques and employ programs that may require a series of 
information and a higher level of complexity. Thus, the intention herein is to investigate how thickness and resilience modulus variations affect flexible pavement performance prediction by applying AASHTO mechanistic-empirical design method and ELSYM5 computer program. This study aims to contribute to the identification of data that most influence pavement performance to indicate to designers which parameters need more attention and more detailed collection. As well as, observe if a simplified analysis regarding the stresses and strains in the pavement can produce satisfactory results regarding the prediction of pavement performance.

\section{Methodology}

This section covers the method used in the research development. After definition of analysis general conditions used, the experimental procedure was divided into three stages: the first one consisted of analyzing pavement structures on ELSYM5 program, which was chosen for the research for being public domain and providing a simplified pavement structure analysis; the second stage referred to analyses by AASHTO ME method, using MEPDG software and AASHTOWare® Pavement Design; the last stage consisted of analyzing performance prediction sensitivity according to input parameters for each of the programs used.

\subsection{Analysis General Conditions}

Sensitivity analysis was performed locally, that is, with one parameter variation at a time, maintaining the other ones constant. This analysis used ELSYM5 computer program (public domain), MEPDG (version 1.100) and AASHTOWare ${ }^{\circledR}$ Pavement Design, version 2.1 (annual international license), with the last two being, respectively, the ME method trial and commercial programs of the American Associate of State Highway and Transportation Officials (AASHTO).

The project parameters chosen for analysis were asphalt coating, base and subbase layer thickness, as well as base, subbase and subgrade layer resilience modulus. Distresses were estimated for the 20th project year, considering a tire inflation pressure of $844 \mathrm{kPa}(120 \mathrm{psi})$.

The reference pavement structure adopted in this study was the same as that used by Fontenele (2011) and Fontenele and Fernandes (2014). This is justified by the need to continue the research developed by these authors. The thicknesses used in the sensitivity analysis were based on the recommended values for the asphalt coating thickness by DNIT (2006). The resilience modules followed the same pattern of variations for thickness, so were adopted two values below and one above the modules of the pavement reference structure. The values assigned to thicknesses and resilience modules are also similar to those adopted by Shahji (2006). Table 1 displays reference pavement structure data, as well as values used in the sensitivity analysis. The characteristics of each material adopted in the layers of the structure used in this research are detailed in the study developed by Fontenele (2011).

Table 1: Pavement structure and variations for sensitivity analysis.

\begin{tabular}{c|l|l}
\hline Layer & \multicolumn{1}{|c|}{ Thickness $(\mathbf{c m})$} & Resilience Modulus (MPa) \\
\hline 1 & $7.50 ; 10.00 ; 12.50 * ; 15.00$ & 4,000 \\
2 & $15.00 ; 17.50 ; 20.00^{*} ; 22.50$ & $276 ; 345 ; 400^{*} ; 483$ \\
3 & $20.00 ; 22.50 ; 25.00^{*} ; 27.50$ & $186 ; 197 ; 206^{*} ; 217$ \\
Subgrade & $\infty$ & $48 ; 59 ; 70^{*} ; 79$ \\
\hline
\end{tabular}

* Reference structure, value used only in ELSYM5 simulations. Source: Autors. 


\subsection{Analyses with ELSYM5 Computer Program}

ELSYM5 computer program allows for calculating tensions and deformations in flexible pavements. This study dealt with horizontal traction deformation in the asphalt coating lower fiber, and vertical compression deformation on top of the subgrade, respectively attributed to appearance of fatigue cracking and rutting.

Traffic data used for simulations on ELSMY5 computer program referred to load spectra developed by Fontenele (2011). However, the load values inserted into said computer program were relative to the mean of load intervals considered in the load spectrum construction, in order to simulate spectrum application as a function of axle load.

Deformations were determined at the centers of the loading surfaces and at equidistant points in relation to them. The distance between loading surface centers was $33 \mathrm{~cm}$ for double-wheel single axle, and $120 \mathrm{~cm}$ for double and triple tandem axle.

By calculating maximum deformations, it was possible to determine the mechanistic-empirical Load Equivalency Factor (LEF) relative to cracking, considering the maximum traction deformation in the asphalt coating lower fiber, and relative to permanent deformations, considering the maximum compression deformation on top of the subgrade. To do so, Equation 1 was used, applying an exponent of 3.291 and 4, respectively, as done by Fernandes, Fabbri, Parreira, Sória and Gigante (2002) and by Fontenele and Fernandes (2014).

$$
L E F=\left(\frac{p_{i}}{p_{0}}\right)^{b}
$$

In which:

$$
\begin{array}{ll}
\rho i & \text { Structural response corresponding to analysis load; } \\
\rho 0 & \text { Structural response corresponding to standard axle load; } \\
b & 3.291 \text { for cracking, and } 4.0 \text { for rutting. }
\end{array}
$$

LEF values were calculated for each load interval mean point of each vehicle class and attributed to the corresponding relative frequency values. LEFs were summed for each axle per vehicle analyzed so that weighted load equivalency factors were calculated for cracking and permanent deformation: LEFcracking and LEFrutting.

By summing the LEFs of each axle that composes the vehicles analyzed, it was possible to calculate the mechanisticempirical Vehicle Factor (VF) for each vehicle analyzed. Then, with relative frequency application to vehicle classes and the sum of individual VFs, mean VFcracking and VFrutting were calculated for the fleet circulating on the road.

Finally, the mechanistic-empirical Equivalent Standard Axle Load (ESAL) was calculated for the 20th project year (p), based on equations 2, 3 and 4, relative to fatigue cracking (ESALcracking) and permanent deformations on top of the subgrade (ESALrutting), considering an annual growth rate ( $\mathrm{t}$ ) of $4 \%$, Vn the volume of traffic in year "n", $\mathrm{c}$ is the distribution factor of commercial vehicles in relation to commercial traffic (in both ways) in the design lane, a is the year of the design period.

$$
\begin{gathered}
V_{n}=V_{0}+n \cdot t \\
E S A L=365 \cdot V F \cdot V_{n} \cdot c \\
E S A L=\sum_{a=1}^{a=p} E S A L_{a}
\end{gathered}
$$




\subsection{Analyses by AASHTO ME Method}

Distresses were predicted on MEPDG (version 1.100) and AASHTOWare ${ }^{\circledR}$ Pavement Design, version 2.1 (annual international license), considering the following pre-established performance criteria: initial International Roughness Index (IRI) equal to $1.0 \mathrm{~m} / \mathrm{km}$; final International Roughness Index of $4 \mathrm{~m} / \mathrm{km}$; Top-down cracking equal to $189 \mathrm{~m} / \mathrm{km}$; Class 3, bottom-up fatigue cracking equal to $25 \%$; Thermal cross-sectional cracking equal to $189 \mathrm{~m} / \mathrm{km} ; 6.35 \mathrm{~mm}$ asphalt coating rutting; rutting in the whole pavement equal to $19.5 \mathrm{~mm}$. The confidence level for performance criteria analysis was $90 \%$.

The distresses predicted and considered in this study were: top-down cracking, bottom-up cracking, asphalt coating, subgrade and total permanent deformation, and IRI. Input data relative to materials, traffic and weather were extracted from Fontenele (2011) and Fontenele and Fernandes Junior (2014). For layer material data, hierarchical level 3 was used, while level 1 was adopted for traffic data, since the load spectra elaborated by the authors considered local data.

ELSYM5 computer program allows for calculating tensions and deformations in flexible pavements. This study dealt with horizontal traction deformation in the asphalt coating lower fiber, and vertical compression deformation on top of the subgrade, respectively attributed to appearance

\subsection{Sensitivity Analyses on Mechanistic-Empirical (ME) Methods}

Performance predictions on the pavement analyzed with the aid of ELSYM5 computer program or distress magnitudes calculated through simulations on MPEDG software and AASHTOWare ${ }^{\circledR}$ Pavement Design were adjusted by multiple linear regression models, considering performance prediction as dependent variable, and project parameters as independent ones. The models obtained were tested statistically for significance through the F Test.

Then, regression coefficients (RCs) were inspected, determining which parameters were significant to predict each distress analyzed. This assessment was performed by applying the $\mathrm{T}$ test.

As in the research by Orobio (2010), for statistical analyses of both regression models and regression coefficients, a 95\% confidence interval and a 5\% level of significance were adopted. Thus, those regression models or parameters whose pvalues were lower than the level of significance were deemed significant. The Statistica 10.0 free trial software was used to calculi p-value.

For parameter hierarchization as to influence, the dependent and independent variables of the regression models were standardized, resulting in standardized regression coefficients (SRCs). This standardization allowed for a direct comparison of distress sensitivity as to input parameter variation.

\section{Results and Discussion}

This section presents and discusses results provided by the sensitivity analysis from simulations on ELSYM5, MEPDG and AASHTOWare ${ }^{\circledR}$ Pavement Design software, according to variations in the study layer properties.

Comparisons between the adjustment performed for lifespan prediction, calculated from structural responses determined by ELSYM5, and the adjustment predicted by the regression models are displayed in Figure 1. 
Figure 1: ESAL values calculated through results of simulations on ELSYM5 versus values predicted by multiple regression models.
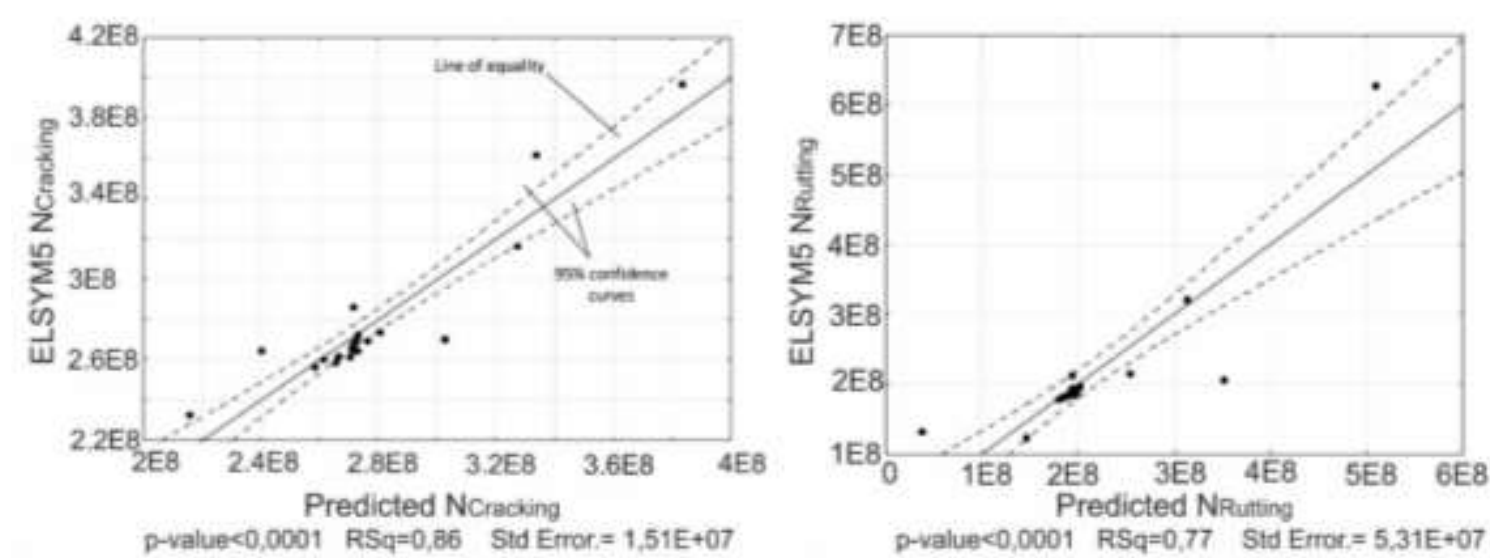

Source: Authors.

In Figure 1, the line of equality indicates where results obtained from simulations on ELSYM5 and regression model results are equal. Thus, the vertical distance between this line and a point is the difference between the program output data and the value estimated by the model. Dotted lines demarcate the $95 \%$ confidence interval.

The significance test applied to the regression model revealed a significant adjustment, proved by p-values $(<0.0001)$ and by the coefficients of multiple determination (R2) of 0.86 and 0.77 , which indicate that the models explain in $86 \%$ the variability of fatigue cracking and in $77 \%$ the variability of permanent deformation around its mean, thus a good regression model means that distresses variations can be explained by input variables.

Comparisons between distress values estimated by MEPDG software and by AASHTOWare ${ }^{\circledR}$ Pavement Design and values predicted by adjusted regression models are exposed in Figures 2 and 3, respectively. 
Figure 2: Values obtained from simulations on MEPDG software versus values predicted by multiple regression models

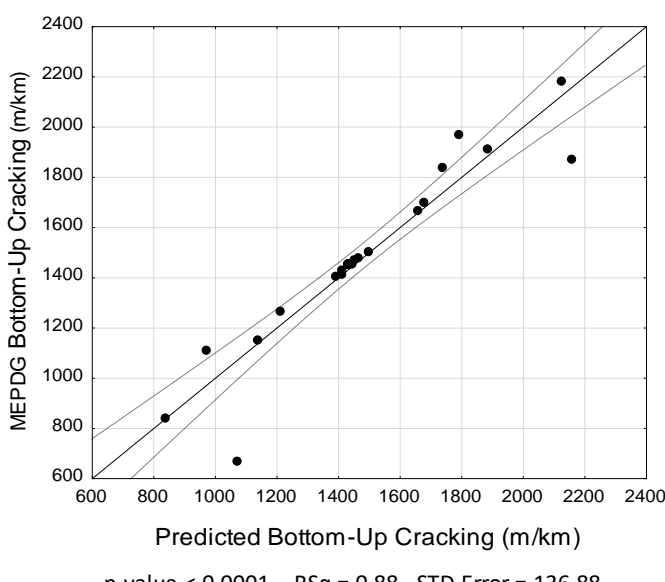

$\mathrm{p}$-value $<0.0001 \quad \mathrm{RSq}=0.88$ STD Error $=136.88$

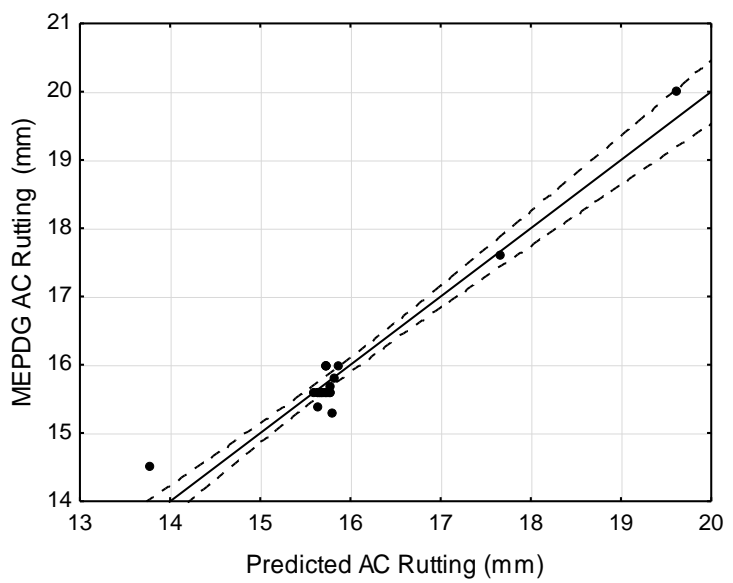

$p$-value $<0.0001 \quad R S q=0.94$ STD Error $=0.2846$

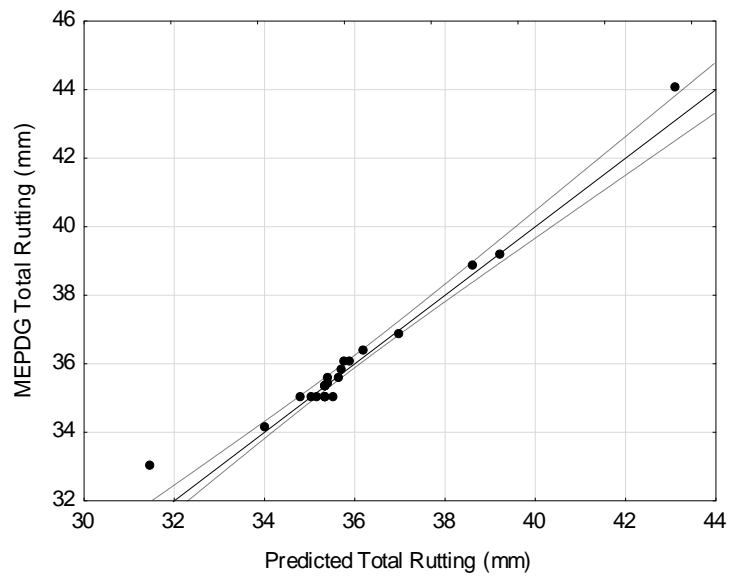

$\mathrm{p}$-value $<0.0001 \quad \mathrm{RSq}=0.96$ STD Error $=0.4875$

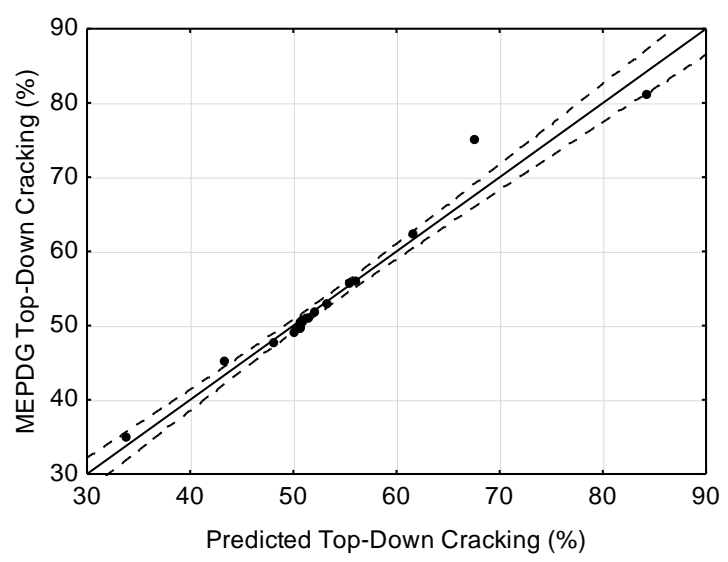

$\mathrm{p}$-value $<0.0001 \quad \mathrm{RSq}=0.96$ STD Error $=2.1397$

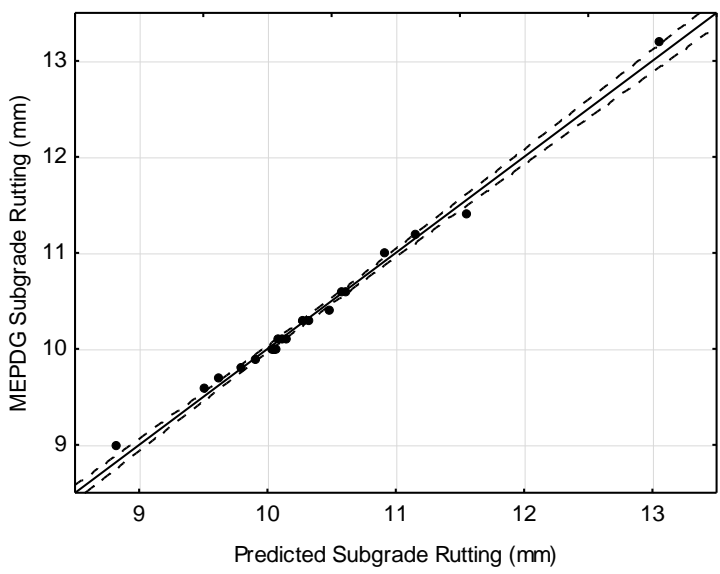

p-value $<0.0001 \quad$ RSq $=0.99$ STD Error $=0.0878$

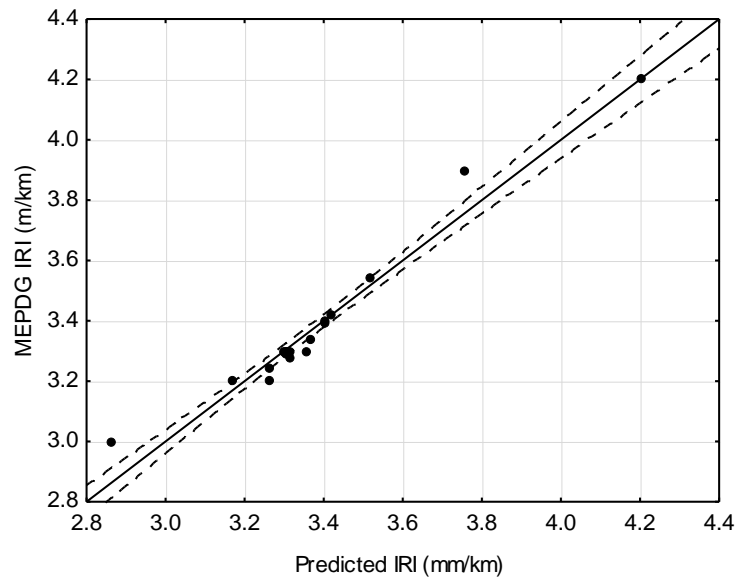

p-value $<0.0001 \quad R S q=0.96$ STD Error $=0.0554$

Source: Authors. 
Figure 3: Values obtained from simulations on AASHTOWare® Pavement Design software versus values predicted by multiple regression models.
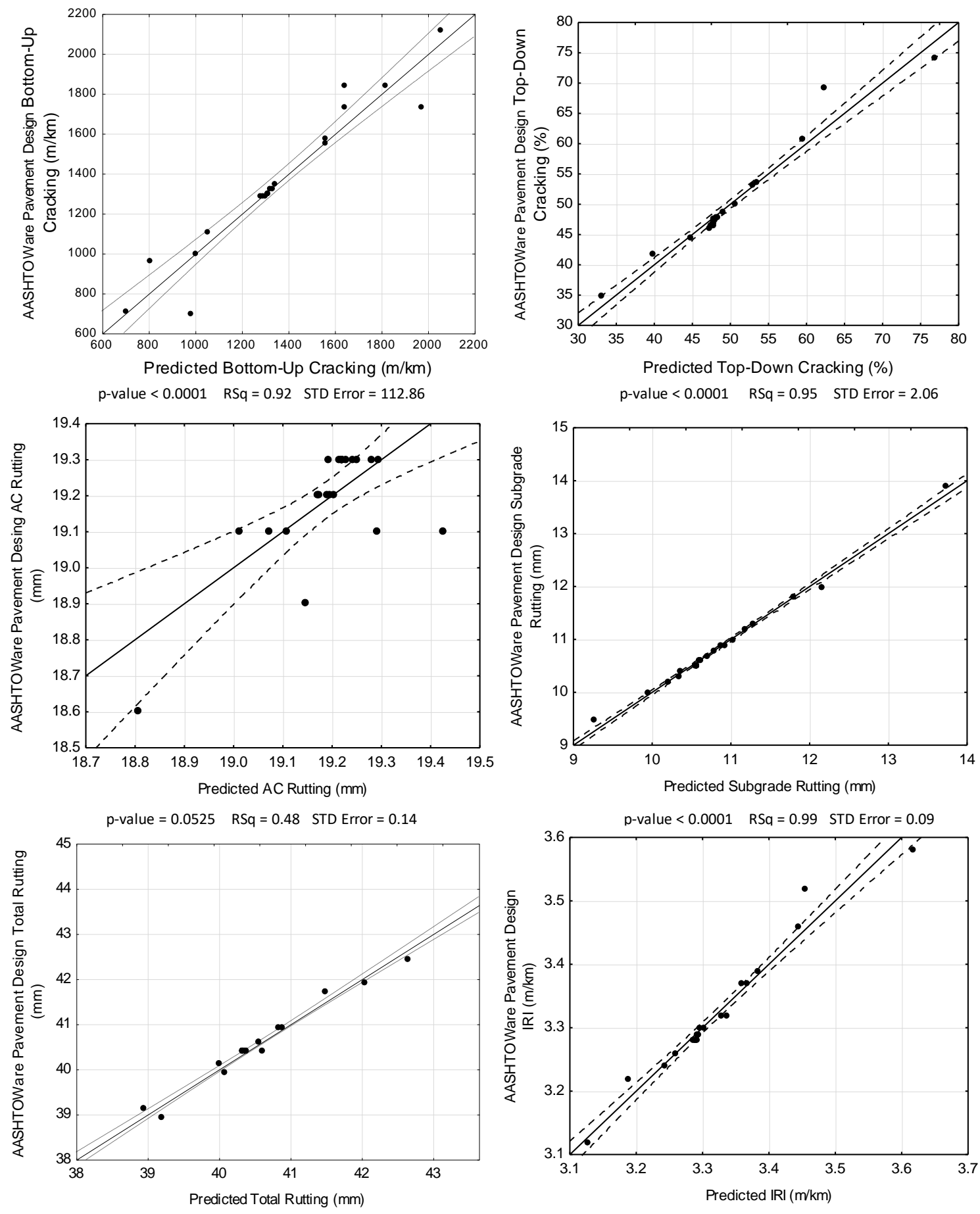

p-value $<0.0001 \quad \mathrm{RSq}=0.98$ STD Error $=0.15$

p-value $<0.0001 \quad R S q=0.96$ STD Error $=0.02$

Source: Authors.

The p-values $<0.0001$, obtained for the hypothesis tests regarding the regression models, indicate that the adjustment was significant. Thus, it is possible to verify that the adjustment performed was significant for all cases, except for all coating permanent deformations estimated by AASHTOWare ${ }^{\circledR}$ Pavement Design, since it was the only adjustment with p-value higher than the significance interval of $5 \%$ used and with a 0.44 coefficient of multiple determination. For all other adjustments, the p- 
value calculated by the test was lower than $5 \%$, and the coefficients of multiple determination (R2) were higher than 0.90 , indicating that more than $90 \%$ of all variations in estimated distress values are explained by variations in input parameters.

After determination of the significance of the multiple regression models adjusted to the results obtained with the simulations, the Regression Coefficients were standardized for comparative analysis as to performance prediction sensitivity according to input parameter variations. Figure 4 presents the SRC obtained for the models adjusted to estimated lifespan from analyses on ELSYM5.

Figure 4: SRC for lifespan from analyses on ELSYM5.

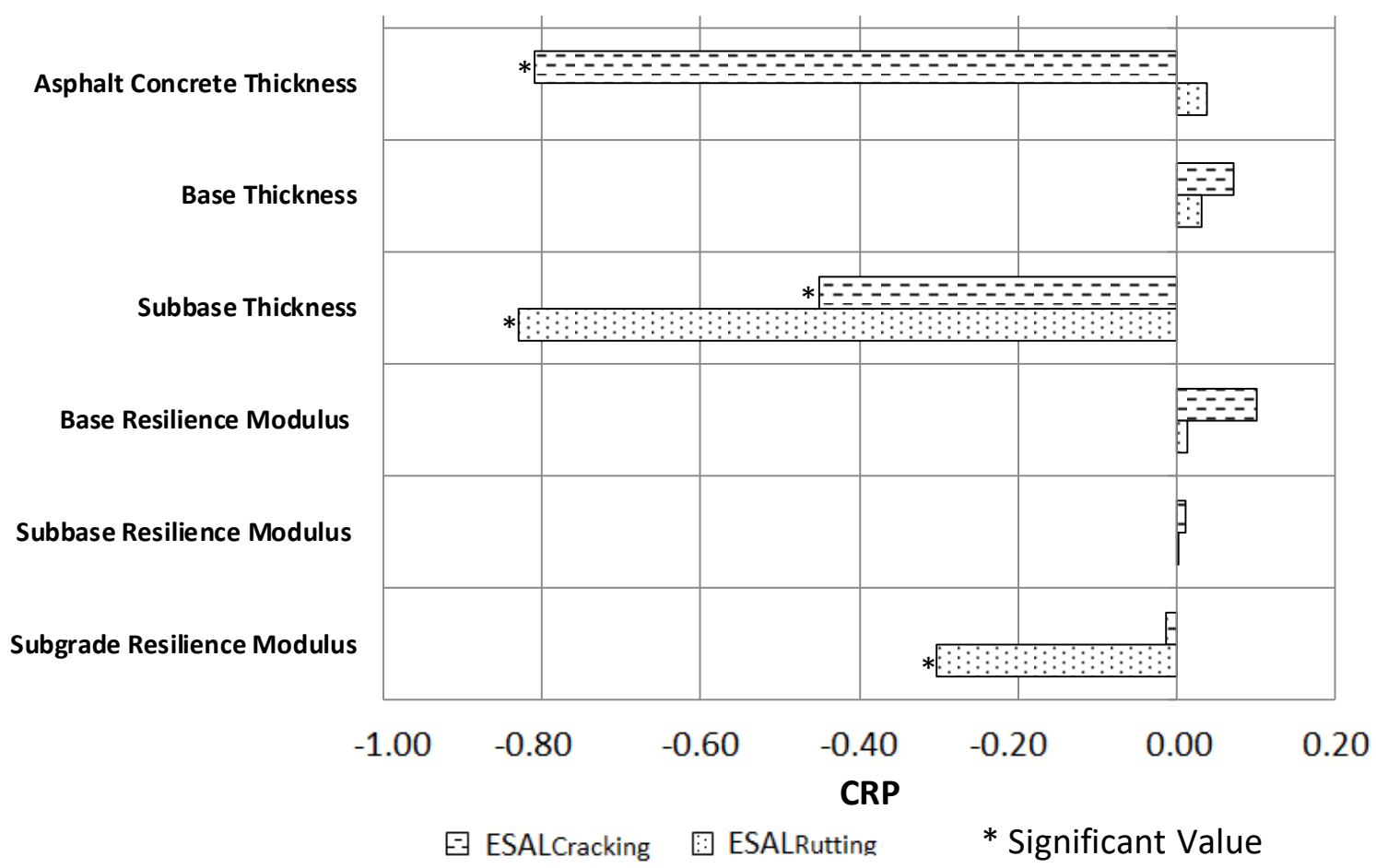

Source: Authors.

Pavement lifespan prediction was significantly sensitive to variations in coating and subbase thickness and in subgrade resilience modulus. The values obtained for the SRCs of these parameters were all negative, that is, as the values of parameters increase, the predicted ESAL number decreases.

In contrast, Figures 5 and 6 show, respectively, the sensitivity analysis concerning influence of input parameters, for the study case, on each distress prediction by AASHTO ME method trial and commercial programs.

The higher sensitivity of both programs in predicting all values of the distresses analyzed was verified for coating thickness variations. The parameter increase caused a decrease in distress measures because they have negative SRCs, except for coating permanent deformation predicted by AASHTOWare ${ }^{\circledR}$ Pavement Design, which has positive SRC, a fact that may be associated with changes in the program routine.

It is possible to observe through the SRCs that, on both AASHTO ME method programs, bottom-up cracking was more sensitive to variations in coating thickness, base resilience modulus, subgrade resilience modulus, and base thickness, in that order. Subbase thickness and resilience modulus variations did not significantly affect the prediction of this distress magnitudes.

Moreover, differences in predicted values for distresses with the use of the trial and commercial programs may be related to the fact that AASHTOWare ${ }^{\circledR}$ Pavement Design uses a higher number of weather clockwise data points compared to MEPDG software, as highlighted by Kim et al. (2013). The trial program has also gone through constant changes for error 
solution and system adjustment until the commercial version was launched. Thus, these improvements may have affected some of the program internal routines concerning the consideration of some input parameters, leading to different results.

It is common to verify differences between results of simulations in test and commercial versions of softwares, that happens because of improve development and errors corrections. That fact is not able to null the application of the software, just prove changes of the routine software.

Figure 5: SRC for the magnitude of the distress predicted by MEPDG software.

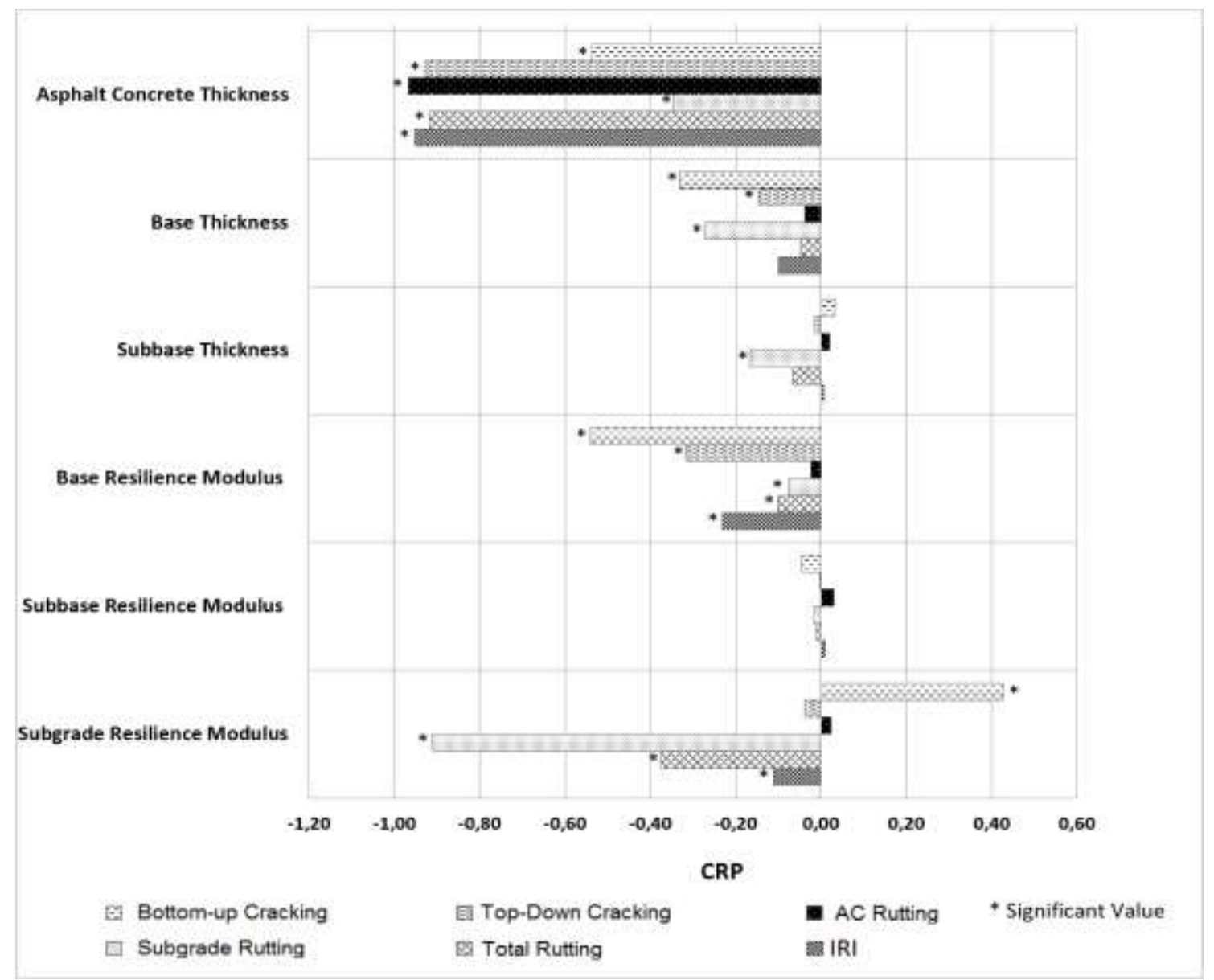

Source: Autors. 
Figure 6: SRC for the magnitude of the distress predicted by AASHTOWare ${ }^{\circledR}$ Pavement Design.

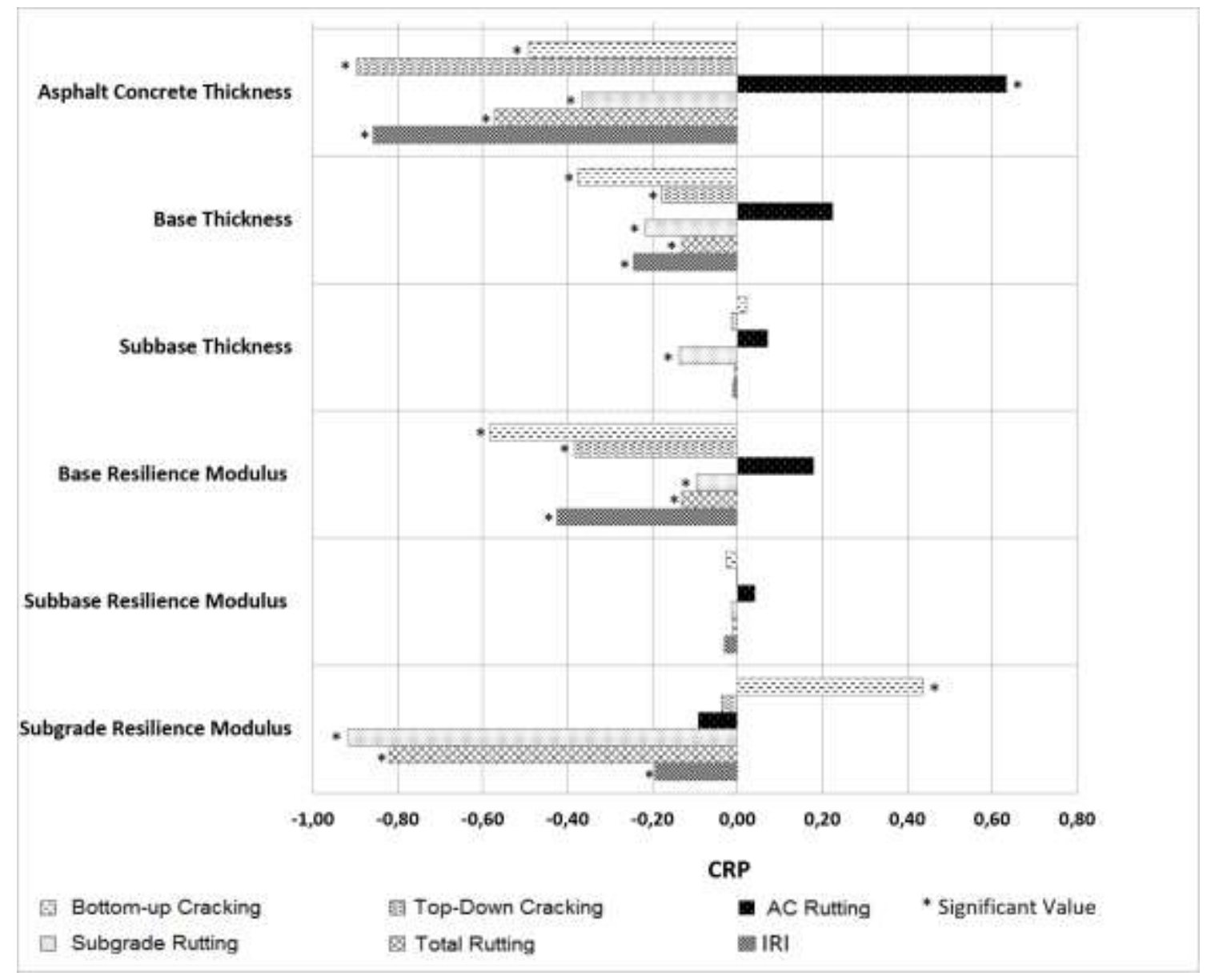

Source: Autors.

Comparing both methods applied, it is possible to notice that, for the study case, significant parameters are inversely proportional to performance indicators.

When it comes to sensitivity concerning fatigue cracking, for ELSYM5, only coating and subbase thickness was significant, while AASHTO ME method presents coating and base thickness, and base and subgrade resilience modulus as significant, for both programs.

As for permanent deformations, ELSYM5 is sensitive only to variations in subbase thickness and in subgrade resilience modulus. On the other hand, considering for AASHTO ME method only deformations on top of the subgrade, besides these parameters, coating and base thicknesses and base resilience modulus are also significant for their prediction.

Comparing results obtained with the simulations on ELSYM5 for permanent deformation and with total deformation values calculated by means of AASHTO ME method trial and commercial programs, ELSYM5 results showed sensitivity to two significant parameters: subbase thickness and subgrade resilience modulus. For MEPDG software, in its turn, the intensity of this distress was sensitive to variations in coating thickness and in base and subgrade resilient modules. Now, for AASHTOWare ${ }^{\circledR}$ Pavement Design, additionally to the same parameters already mentioned for MEPDG software, distress values were also sensitive to base thickness variations.

The differences found between the methods studied may correlate with the fact that AASHTO ME method considers a higher number of parameters for performance estimates compared to those necessary for simulations on ELSYM5, besides using dynamic elastic modulus for asphalt mixture, which is estimated by means of a correlation equation calibrated to American mixtures, while a fixed value was adopted for this parameter in simulations on ELSYM5. 
Traffic consideration may also have had an influence on the consideration of different parameters as significant, since, for simulations on ELSYM5, a way to simulate load spectrum application was adopted. However, AASHTO method does not state clearly how load spectra are applied to programs for pavement performance estimates.

Another fact that may have been relevant is weather interference, considered in AASHTO ME method and disregarded in the method used for performance estimate with ELSYM5.

As for the other distress magnitudes predicted only by AASHTO ME method programs, as displayed in Figures 5 and 6 , it is worth noting that bottom-up cracking was more sensitive to variations in coating thickness, base resilience modulus, subgrade resilience modulus, and base thickness.

For coating permanent deformations, only on MEPDG software there was no significant influence of coating thickness on intensity prediction for this distress. For prediction of coating permanent deformation values, it is important to point out that, for AASHTOWare ${ }^{\circledR}$ Pavement Design, a coating thickness increase raised the distress value by $3 \%$, contrary to expectations, since a thickness increase reduces tension concentration and, consequently, deformations decrease.

Regarding prediction of IRI values for the 20th project year, it was possible to observe that, for MEPDG software, the greatest influence was that of coating thickness, followed by variations in base and subgrade resilience modulus. On the other hand, for AASHTOWare $®$ Pavement Design, distress magnitudes were more sensitive to variations in coating thickness, base resilience modulus, base thickness, and subgrade resilience modulus.

\section{Conclusion}

With the method applied to the research, considering the specific boundary conditions adopted, it was possible to comprehend how pavement performance is influenced by variations in the parameters assessed using the ME approach.

For the study case, about the approach using ELSYM5 program, coating thickness and subgrade resilience modulus are the parameters with the greatest influence on performance prediction. With the application of AASHTO ME method programs, it has been found that coating and base thicknesses and base and subgrade resilient moduli are more influent in predicting distress magnitudes.

Furthermore, the research showed that small variations in the parameters studied may cause significant percentage changes in distresses predicted by the methods studied. However, there still is a need for deeper researches that take into consideration other combinations as to traffic, weather, properties of materials, etc., as well as analyses on factorial sensitivity, in order to better understand the inter-relation of independent variables in performance prediction models.

Additionally, ELSYM5 program, for being a public domain software, proved to be a viable alternative to the application of a mechanistic-empirical pavement design method because, despite presenting a simplified analysis as to pavement tension and deformation, it can produce good results as to performance estimates.

AASHTO ME method proved to be an interesting design tool due to its sensitivity to input data for the study case, but it has disadvantages relative to the program purchase costs. Also, for the method better performance, it is worth emphasizing the need for developing national and local calibration factors for projects in Brazilian conditions.

Finally, it is worth stressing the importance of sensitivity analyses before application of any program for ME pavement design. Oftentimes, the methods used are adapted and require adjustments and validations for the conditions in which they will be applied. Moreover, transfer functions are calibrated to distress estimates usually by means of national databases, which may not reflect an optimal condition for a regional project, requiring sensitivity studies in order to calibrate coefficients and validate the application of an ME method. It should be noted that the programs support decision making; therefore, knowledge about their strengths and limitations is of paramount importance for their use to be able to raise the quality of projects developed in engineering practice. 


\section{Acknowledgments}

The authors would like to thank Araucaria Foundation (State of Paraná Research Foundation) for financial support for the research (Call 14/2011 - Protocol No 4685) and to the National Council for Scientific and Technological Development (CNPq) for the scholarship granted.

\section{References}

Alexandre, L. H. C., Alves, S. A. M., Borba, P. C. S., Réus, T. F., Teixeira, R., Silva, C. A. P., Jr., \& Fontenele, H. B. (2015). Sensibilidade dos pavimentos flexíveis às variações dos módulos de elasticidade. Revista de Engenharia e Tecnologia, 7 (1), 71-78.

Cooper, S. B., Elseifi, M. A., \& Mohammad, L. N. (2012). Parametric Evaluation of Design Input Parameters on the Mechanistic-Empirical Pavement Design Guide Predicted Performance. International Journal of Pavement Research and Technology, 5 (4), 218-224.

Departamento Nacional de Infraestrutura e Transportes - DNIT (2006). Manual de Pavimentação (3a ed.), IPR.

Fernandes, J. L., Jr., Fabbri, G. T. P., Parreira, Sória, M. H. A., \& Gigante, A. C. (2002). Efeitos dos pneus trelleborg sobre pavimentos asfálticos. Minerva, 2 (1), 13-24.

Fontenele, H. B. (2011). Representação do Tráfego de Veículos Rodoviários de Carga através de Espectros de Carga por Eixo e seu Efeito no Desempenho dos Pavimentos. 2011. 287 p. Tese de Doutorado (Engenharia de Transportes). Universidade de São Paulo, São Paulo, Brasil.

Fontenele, H. B., \& Fernandes, J. L., Jr. (2014). O efeito da caracterização do tráfego no desempenho do pavimento flexível. Ciência \& Engenharia, 23 (1), 0916. $10.14393 / 19834071.2014 .24552$

Harsini, I., Haider, S. W., Brink, W. C., Buch, N., \& Chatti, K. (2018). Investigation of significant inputs for pavement rehabilitation design in the PavementME. Canadian Journal of Civil Engineering, 45 (5), 386-392. 10.1139/cjce-2017-0046

Hossain, N., Singh, D., \& Zaman, M. (2016). Sensitivity of traffic input parameters on rutting performance of a flexible pavement using Mechanistic Empirical Pavement Design Guide. International Journal of Pavement Research and Technology, 9 (6), 450-459. 10.1016/j.ijprt.2016.09.003

Koshigoe, A. S. H., Zanoni, F. C. V., Silva, C. A. P., Jr., \& Fontenele, H. B. (2019). Effect of variation of the average daily volume and traffic growth rate on flexible pavements performance. Ingeniare. Revista chilena de ingeniería, 27 (1), 58-68. 10.4067/S0718-33052019000100058

Li, Q. J., Minnekanti, S. P., Yang, G., \& Wang, C. (2019). Traffic inputs for pavement ME design using Oklahoma data. International Journal of Pavement Research and Technology, 12 (2), 154-160. 10.1007/s42947-019-0020-5

Li, R., Schwartz, C. W., Kim, S., \& Ceylan, H. (2012). Local sensitivity of mechanistic-empirical flexible pavement performance predictions to unbound material property inputs. Proc., GeoCongress 2012: State of the Art and Practice in Geotechnical Engineering, Oakland, California, United States, 1495-1504. $10.1061 / 9780784412121.154$

Li, X., Zhang, R., Zhao, X., \& Wang, H. (2014). Sensitivity Analysis of Flexible Pavement Parameters by Mechanistic-Empirical Design Guide. Applied Mechanics and Materials, 590, 539-545. 10.4028/www.scientific.net/AMM.590.539

Mai, D., Turochy, R., \& Timm, D. H. (2013). Correlation-based clustering of traffic data for the mechanistic-empirical pavement design guide. Transportation Research Record: Journal of the Transportation Research Board, 2339 (1), 104-111. 10.3141/2339-12

Mai, D., Turochy, R., \& Timm, D. H. (2014). Sensitivity of Flexible Pavement Thickness to Traffic Factors in Mechanistic-Empirical Pavement Design. Journal of Transportation Engineering, 140 (2), 04013005-1 - 04013005-7. https://doi.org/10.1061/(ASCE)TE.1943-5436.0000628

Orobio, A. (2010). Sensitivity analysis of flexible pavement performance parameters in the mechanistic-empirical design guide. Doctoral Dissertation. College of Engineering and Mineral Resources, West Virginia University, Morgantown, West Virginia, USA. Available: https://researchrepository.wvu.edu/etd/2979

Orobio, A., \& Zaniewski, J. (2011). Sampling-based sensitivity analysis of the mechanistic-empirical pavement design guide applied to material inputs. Transportation Research Record: Journal of the Transportation Research Board, 2226 (1), 85-93. 10.3141/2226-09

Orobio, A., \& Zaniewski, J. P. (2012). Using the mechanistic-empirical pavement design guide for material selection. Revista Facultad de Ingeniería Universidad de Antioquia, (64), 138-149.

Orobio, A., \& Zaniewski, J. P. (2013). Sensitivity of the mechanistic-empirical pavement design guide to traffic inputs: a space-filling approach. Road Materials and Pavement Design, 14 (3), 735-746. 10.1080/14680629.2013.816248

Pelisson, N. D., Fernandes, J. L., Jr., Silva, C. A. P., Jr., \& Fontenele, H. B. (2015). Avaliação de desempenho pelo MEPDG: o efeito da variação de espessuras de pavimentos flexíveis. Journal of Transport Literature, 9 (1), 20-24. 10.1590/2238-1031.jtl.v9n1a4

Ranadive, M. S., \& Tapase, A. B. (2016). Parameter sensitive analysis of flexible pavement. International Journal of Pavement Research and Technology, 9 (6), 466-472. 10.1016/j.ijprt.2016.12.001

Santos, T. A., Silva, C. A. P., Jr., \& Fontenele, H. B. (2019). The effect of axle load spectra from AASHTO method on flexible pavement performance. Acta Scientiarum - Technology, 41 (1), e35117. 10.4025/actascitechnol.v41i1.35117 
Research, Society and Development, v. 10, n. 8, e42610817466, 2021

(CC BY 4.0) | ISSN 2525-3409 | DOI: http://dx.doi.org/10.33448/rsd-v10i8.17466

Schwartz, C. W., Li, R., Ceylan, H., Kim, S., \& Gopalakrishnan, K. (2013). Global Sensitivity Analysis of mechanistic-Empirical Performance Predictions for Flexible Pavements. Transportation Research Record: Journal of the Transportation Research Board, 2368 (1), 12-23. 10.3141/2368-02

Shajhi, S. Sensitivity Analysis of AASHTO's 2002 Flexible and Rigid Pavement Design Methods. Master of Science Thesis, Department of Civil \& Environmental Engineering, College of Engineering and Computer Science, University of Central Florida. Orlando, Florida. Available: https://stars.library.ucf.edu/etd/1062

Vidotto, J. P., \& Fontenele, H. B. (2014). Efeito da variação da espessura do revestimento nas respostas estruturais do pavimento flexível. Semina: Ciências Exatas e Tecnológicas, 34 (2), 155-166. 10.5433/1679-0375.2013v34n2p155

Yang, X., You, Z., Hiller, J., \& Watkins, D. (2017). Sensitivity of flexible pavement design to Michigan's climatic inputs using pavement ME design. International Journal of Pavement Engineering, 18 (7), 622-632. 10.1080/10298436.2015.1105373 